\title{
Impacto produtivo na inclusão de germoplasma Booroola em rebanho Corriedale
}

Fernando Amarilho-Silveira ${ }^{1}$

\section{Resumo}

O objetivo desta nota é apresentar alguns resultados referentes ao impacto produtivo no primeiro ano de inclusão do germoplasma Booroola em um rebanho da raça Corriedale. Os dados foram tomados da produção de um rebanho geral da raça Corriedale, nascida no ano de 2013 . Foram acasaladas 25 ovelhas com um carneiro Booroola (BN) e 50 com dois carneiros não Booroola (NN). As filhas do carneiro BN se mostraram mais resistentes aos parasitos gastrointestinais. Por outro lado, as filhas dos carneiros NN apresentaram menores valores para qualidade do fiado e maior fator de conforto. Com a inclusão do sangue Booroola neste rebanho, foram obtidos ganhos genéticos para resistência a parasitos gastrointestinais.

Palavras-chave: Diferença esperada na progênie. Ovinos. Resistência a parasitos gastrointestinais.

\section{Introdução}

Os sistemas de produção ovina buscam, cada vez mais, à eficiência produtiva. Logo, a aquisição de reprodutores é um tema de grande importância, em que devemos eleger animais que sejam mais produtivos em sistema extensivo sobre campos naturais do Rio Grande do Sul, ou seja, nada vale adquirir reprodutores fenotipicamente superiores se não dermos as condições necessárias para a expressão do seu potencial. Neste sentido, muitas vezes, um animal criado em um sistema mais próximo a realidade de produção pode proporcionar melhores resultados do que animais superiores, fenotipicamente criados em sistemas ótimos.

Algumas características como precocidade, maior velocidade de crescimento, melhor conversão alimentar e prolificidade são critérios buscados na importação de materiais genéticos especializados. Para prolificidade, tem-se animais portadores do gene Booroola.

O fenótipo Booroola foi identificado em ovelhas Merino na Austrália, no final da década de setenta, como sendo causado por um gene principal com efeito aditivo sobre a taxa de ovulação e dominância sobre o tipo de parto. No Brasil a mutação Booroola foi introduzida pela Embrapa Pecuária Sul por meio da importação de carneiros portadores, no início da década de oitenta, quando foi avaliada a produtividade das ovelhas mutantes nas condições extensivas de criação do Rio Grande do Sul. No entanto, notou-se um aumento na quantidade de cordeiros nascidos acompanhado de altas taxas de mortalidade (SOUZA et al., 2009).

O uso dessa mutação no Brasil vem sendo avaliado em rebanhos comerciais das raças Texel e Corriedale e já resultou no desmame de mais de 130 \% cordeiros por ovelha acasalada e na produção de cordeiros com peso ajustado aos 100 dias, entre 20 e $30 \mathrm{~kg}$ (SOUZA et al., 2006).

Em 2003 foi iniciado um programa de introgressão assistida por diagnóstico molecular dessa mutação em rebanhos. Foram feitas pelo menos cinco progênies de retro-cruzamento, totalizando

1 Universidade Federal de Pelotas, mestrando do Programa de Pós-Graduação em Zootecnia. Pelotas, Rio Grande do Sul, Brasil. amarillo@zootecnista.com.br. Rua Santa Cruz, 1184, Centro, Petotas (RS), CEP: 96015-710. 
mais de dois mil acasalamentos orientados pela genotipagem. No momento, estão disponíveis no mercado carneiros das raças Texel e Corriedale, portadores da mutação Booroola (BN), certificados por genotipagem e com padrão racial atestado pela Associação Nacional de Criadores de Ovinos (SOUZA et al., 2009).

Desta forma, rebanhos que introduziram carneiros BN obtiveram aumento significativo na produtividade quando suas filhas vieram a parir e desmamarem sua cria. Portanto não se encontram dados na bibliografia brasileira da superioridade em relação a outras características produtivas, como resistência a parasitos gastrointestinais, peso corporal ao desmame e a um ano de idade e características de qualidade da lã nos filhos desses carneiros, tendo como base materna um rebanho geral.

Neste sentido, o objetivo desta nota é trazer alguns resultados referentes ao impacto produtivo no primeiro ano de inclusão do germoplasma Booroola em um rebanho da raça Corriedale e confrontar com os dados produtivos de outros carneiros da mesma raça, mas não portadores da mutação.

\section{Material e métodos}

Os dados foram tomados da produção de um rebanho geral da raça Corriedale, nascida no ano de 2013, oriundos de uma propriedade rural particular situada nas coordenadas 31'57'19.40"S e 5330'56.78"O. Foram acasaladas 25 ovelhas com um carneiro Corriedale, portador da mutação Booroola (BN), e 50 com dois carneiros Corriedale não portadores da mutação (NN).

Os nascimentos ocorreram no período de 15 de agosto a 10 de setembro de 2013. Assim, as progênies foram constituídas de nove cordeiras filhas do carneiro portador da mutação Booroola e 22 cordeiras filhas dos demais carneiros.

Após o nascimento, todas as cordeiras (juntamente com as devidas mães) foram manejadas no mesmo ambiente. 0 desmame foi feito no mês de janeiro de 2014 , quando as cordeiras completavam cinco meses de idade, momento em que começaram as avaliações da resistência a parasitos gastrointestinais e do peso corporal ao desmame. O peso corporal (em quilogramas) a um ano de idade, diâmetro médio das fibras de lã, fator de conforto e qualidade do fiado foram aferidos aos doze meses de idade.

A fenotipagem para a característica de resistência a parasitos gastrointestinais foi realizada pela contagem de ovos por gramas de fezes (OPG) em três momentos: aos cinco (após o desmame), aos sete e aos doze meses de idade, seguindo a metodologia proposta por Goldberg et al. (2011).

Para as características de qualidade de lã, como diâmetro médio das fibras de lã (em micras), fator de conforto (em porcentagem) e qualidade do fiado (em micras), as amostras de lã, coletadas aos doze meses de idade, entre a última e penúltima costela esquerda, cerca de $20 \mathrm{~cm}$ de distância das vértebras lombares, foram submetidas à análise objetiva pelo Optical Fibre Diameter Analysis OFDA 2000.

Todos os dados aferidos foram submetidos à correlação de Pearson entre si, dentro das suas devidas linhas genéticas, pelo pacote estatístico SAS 9.0, ou seja, cordeiras filhas do carneiro BN ou cordeiras filhas dos carneiros NN. Seus dados produtivos foram correlacionados independentemente do conjunto de dados obtidos pelo outro grupo genético. Os dados foram submetidos à análise de variância pelo pacote estatístico SAS 9.0 para comparação entre as proles dos dois grupos genéticos.

Para os valores que diferiram estatisticamente $(p<0,05)$ pela análise de variância, foram feitas as estimativas de mérito genético do carneiro BN em relação aos carneiros $N N$, expressos em diferença esperada na progênie, pelo Proc mixed do pacote estatístico SAS 9.0. 


\section{Resultados e discussão}

As características obtidas para as cordeiras filhas dos carneiros NN apresentaram correlações significativas ( $p<0,05$ ) entre o peso corporal ao desmame e a um ano de idade; o diâmetro médio das fibras de lã e o fator de conforto; o diâmetro médio das fibras de lã e a qualidade do fiado; entre o fator de conforto e a qualidade do fiado. As filhas do carneiro BN apresentaram correlações significativas ( $p<0,05$ ) entre o diâmetro médio das fibras de lã e o peso corporal ao desmame; o diâmetro médio das fibras de lã e o fator de conforto; o diâmetro médio das fibras de lã e a qualidade do fiado; a qualidade do fiado e o peso corporal a um ano de idade; entre o fator de conforto e a qualidade do fiado (Tabela 1).

Assim, $83 \%$ das cordeiras filhas dos carneiros NN que apresentaram maiores pesos corporais ao desmame também apresentaram maiores pesos corporais a um ano de idade. Logo, nas que foram encontrados menores diâmetros médios das fibras de lã, também serão encontrados maiores fatores de conforto e melhores qualidades do fiado (de menores diâmetros). Dessa forma, quanto maior for o fator de conforto, menor será o diâmetro esperado nos fios (qualidade do fiado).

Tabela 1. Correlação entre as características avaliadas, diagonal superior: cordeiras filhas dos carneiros NN; diagonal inferior: filhas do carneiro BN.

\begin{tabular}{|c|c|c|c|c|c|c|}
\hline $\begin{array}{l}\text { NN } \\
\text { BN }\end{array}$ & $\mathrm{OPG}^{1}$ & PCD & PCAA & DF & FC & QF \\
\hline $\mathrm{OPG}^{1}$ & 1 & $-0,04$ & 0,006 & 0,14 & $-0,17$ & 0,17 \\
\hline PCD & $-0,18$ & 1 & $0,83 * * *$ & $-0,17$ & 0,18 & $-0,17$ \\
\hline PCAA & $-0,12$ & 0,61 & 1 & 0,05 & 0,08 & $-0,14$ \\
\hline DF & 0,36 & $-0,68 * *$ & $-0,63$ & 1 & $-0,90 * * *$ & $0,94 * * *$ \\
\hline $\mathrm{FC}$ & $-0,50$ & 0,46 & 0,60 & $-0,94^{* *}$ & 1 & $-0,98 * * *$ \\
\hline QF & 0,49 & $-0,57$ & $-0,67^{*}$ & $0,95^{* * *}$ & $-0,98 * * *$ & 1 \\
\hline
\end{tabular}

${ }^{1} \mathrm{OPG}$ - avaliação de resistência a parasitos gastrointestinais, expresso pela contagem média de ovos por gramas de fezes transformados a logaritmo neperiano (referente aos três momentos de avaliação); PCD - peso corporal ao desmame (cinco meses de idade); PCAA - peso corporal a um ano de idade; DF - diâmetro médio das fibras de lã; FC - fator de conforto; QF - qualidade do fiado.

$* * * P<0,0001$

$* * P<0,01$

$* P<0,05$

Fonte: Elaborada pelo autor (2017)

O diâmetro médio das fibras de lã representa 80 \% da remuneração do produto, ou seja, quanto mais finas forem as fibras, maior será a remuneração pelo produto lanoso (AMARILHO-SILVEIRA; BRONDANI; LEMES, 2015a). Por outro lado, o fator de conforto representa a porcentagem de fibras que apresentam diâmetro inferior a 30 micras, dessa maneira, quanto maior for esse fator, melhor qualidade terá o tecido originado por essa lã. Conforme relatado por Neimaur et al. (2015), em relação aos estudos realizados por CSIRO (Commonwealth Scientific and Industrial Research Organisation), tem-se demonstrado que o conforto proporcionado pelos tecidos, quando em contato com a pele, está relacionado com o diâmetro que possui os extremos da fibra que sobressaem do tecido. Assim, vem-se estabelecendo que, se os extremos da fibra mais grossos que 30 micras não superam $5 \%$ do total, o conforto a nível de pele é aceitável para a maioria dos usuários.

A qualidade do fiado é um cálculo que estima o diâmetro médio das fibras pós-fiado, o qual considera apenas as fibras que serão manufaturadas em tecidos, descartando os Blouss. Esse, por sua vez, é um subproduto da industrialização sendo destinado à confecção de panos e não tecidos. Os 
Blouss são submetidos ao processo de cardado por estar composto por fibras curtas, abaixo de cinco centímetros e mais finas que 17,1 micras (IWTO, 2015). Assim, quanto mais finos forem os fios passíveis de produção dessa lã, maior será a gama de utilização desses produtos em uma variedade de tecidos; consecutivamente, maior será a valorização desses fios após o processo de industrialização (AMARILHO-SILVEIRA; BRONDANI; LEMES, 2015a).

Para as cordeiras filhas do carneiro BN foi encontrada uma relação que produtivamente é de grande valorização, em que se correlacionaram significativamente $(p<0,05)$ e de maneira negativa o diâmetro médio das fibras de lã e o peso corporal ao desmame, ou seja, próximo a 68 \% das cordeiras que apresentaram maiores pesos corporais ao desmame têm menores diâmetros de fibra. Isso provavelmente reflete o potencial produtivo que têm as filhas do carneiro BN, das quais quanto menor o diâmetro da lã, maior seu valor. O contrário é verdadeiro para o peso e desmame, em que quanto maiores forem esses valores, menor será o tempo hábil para colocá-lo em condições de abate ou antecipar seu primeiro acasalamento.

A relação entre a qualidade do fiado e o peso a um ano de idade se mostrou correlacionada de forma negativa; os animais que apresentaram menores diâmetros de fios, algo próximo a $67 \%$, eram os animais mais pesados a um ano de idade. Esse achado, provavelmente de carácter genético, em que a inclusão do sangue BN como um animal da raça Corriedale, que também sofreu pressão de seleção por características produtivas e não só por de aspecto reprodutivo, incrementou o peso ao desmame e a produção de lã mais fina nesse rebanho. Conforme o Instituto Nacional de Investigacion Agropecuária (2011), se o objetivo de seleção enfatiza uma forte seleção por peso de velo e por peso corporal a um ano de idade e, por sua vez, não se deseja descuidar o diâmetro, deve-se eleger carneiros que se encontrem dentro dos melhores $5 \%$ da população para as duas primeiras características e que sejam médios (50 \%) para diâmetro. Neste sentido, tende-se a aumentar a produtividade, mas manter a qualidade na aquisição dos reprodutores.

Para as características do diâmetro médio das fibras de lã e o fator de conforto, o diâmetro médio das fibras de lã e a qualidade do fiado e o fator de conforto e a qualidade do fiado, os dados das cordeiras filhas do BN correlacionaram semelhantemente às filhas dos carneiros NN.

$\mathrm{Na}$ análise de variância foram encontradas diferenças significativas $(p<0,05)$ para resistência a parasitos gastrointestinais, fator de conforto e qualidade do fiado. As filhas do carneiro BN se mostraram mais resistentes aos parasitos gastrointestinais, apresentando menores cargas parasitárias ao longo do período de avaliação. Por outro lado, as filhas dos carneiros NN apresentaram menores valores para a qualidade do fiado e maior fator de conforto (Tabela 2). Assim, tem-se que as filhas do carneiro BN são mais resistentes aos parasitos gastrointestinais, porém apresentaram menores porcentagens de fibras inferiores a 30 micras e produziram maiores diâmetros de fios. 
Tabela 2. Análise de variância entre as proles dos carneiros BN e NN, média e desvio-padrão.

\begin{tabular}{ccccccc}
\hline Carneiro & OPG1 & PCD & PCAA & DF & FC & QF \\
\hline $\mathbf{B N}(\mathbf{n}=\mathbf{9})$ & $5,86 \pm 1,28$ & $23,94 \pm 3,77$ & $26,93 \pm 2,77$ & $25,30 \pm 1,87$ & $81,65 \pm 9,74$ & $24,96 \pm 2,11$ \\
\hline $\mathbf{N N}(\mathbf{n}=\mathbf{2 2})$ & $6,87 \pm 0,77$ & $24,11 \pm 4,23$ & $28,52 \pm 3,34$ & $24,42 \pm 1,27$ & $88,16 \pm 5,59$ & $23,60 \pm 1,22$ \\
\hline $\mathbf{P r}>\mathbf{F}$ & 0,0110 & 0,9158 & 0,219 & 0,1439 & 0,0287 & 0,0315 \\
\hline
\end{tabular}

${ }^{1} \mathrm{OPG}$ - avaliação de resistência a parasitos gastrointestinais, expresso pela contagem média de ovos por gramas de fezes transformados a logaritmo neperiano (referente aos três momentos de avaliação), em unidade; PCD peso corporal ao desmame (cinco meses de idade), em kg; PCAA - peso corporal a um ano de idade, em kg; DF - diâmetro médio das fibras de lã, em micras; FC - fator de conforto, em porcentagem; QF - qualidade do fiado, em micras.

Fonte: Elaborada pelo autor (2017).

Na Figura 1 é mostrado o mérito genético do carneiro BN em relação aos carneiros NN para as características que diferiram mediante a análise de variância, com valores de -0,43, -2,66 e 0,54, respectivamente, para resistência a parasitos gastrointestinais (OPG), fator de conforto (FC) e qualidade do fiado (QF). Desse modo, podemos dizer que, se comparado a um carneiro com diferença esperada na progênie (DEP) igual a zero para essas três características, o carneiro BN terá uma DEP de -0,43 para OPG, ou seja, será mais resistente; DEP -2,66\% para FC, representando 2,66 \% menos fibras com diâmetro inferior a 30 micras; DEP de 0,54 $\mu$ para QF, significando a produção de fios com 0,54 micras mais grossos. Devido à OPG ser uma característica de elevada variabilidade numérica, ocasionada pela grande dependência ambiental, e por seus dados brutos de contagem de ovos por grama de fezes terem que passar por transformações que os coloquem na normalidade (por apresentarem coeficientes de variação acima de $100 \%$ ), o valor apresentado serve somente para comparação entre dados de animais e não para predição numérica da diminuição da carga parasitária (AMARILHO-SILVEIRA et al., 2015b).

Figura 1. Mérito genético do carneiro BN em relação aos NN, expressado em diferença esperada na progênie para avaliação de resistência a parasitos gastrointestinais, expresso pela contagem média de ovos por gramas de fezes, transformados a logaritmo neperiano (OG), fator de conforto (FC) e qualidade do fiado (QF).

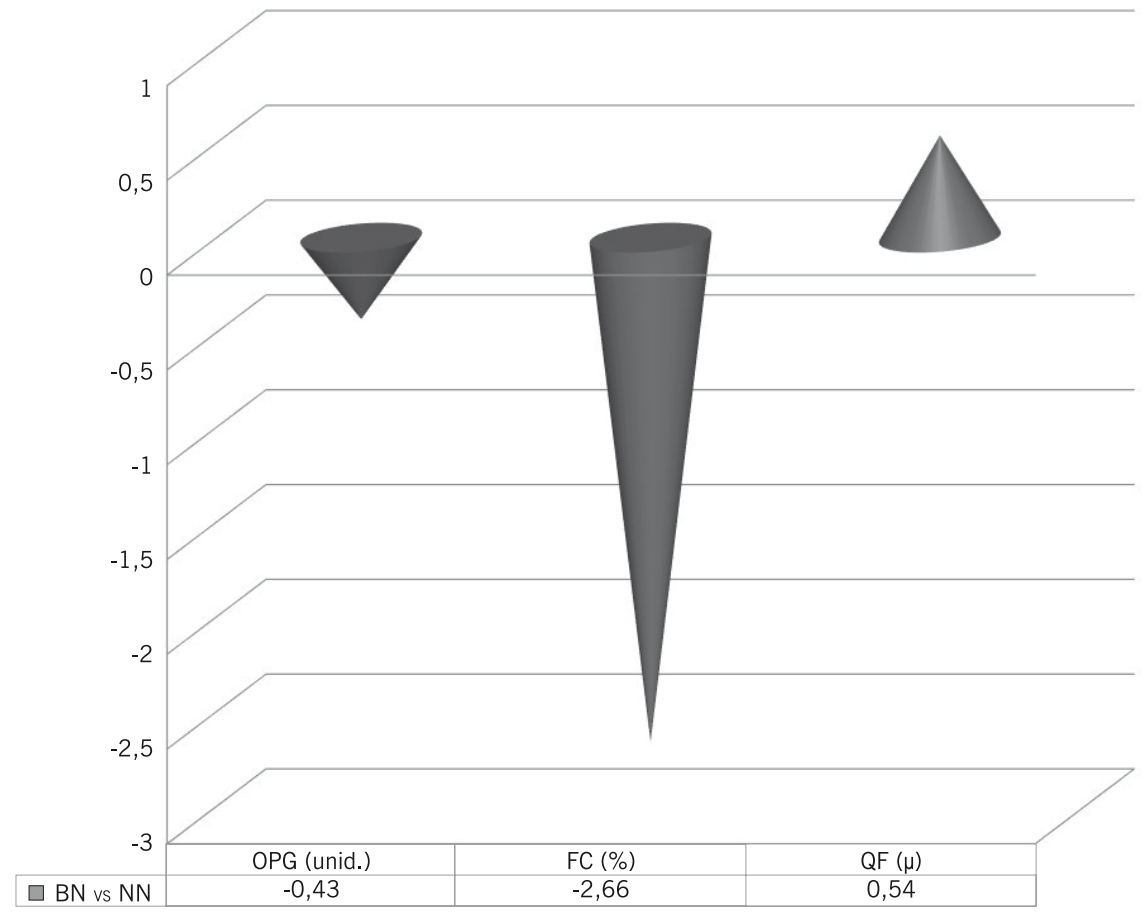

Fonte: Elaborado pelo autor (2017) 


\section{Conclusões}

Os resultados da presente nota indicam que ao incluir o sangue Booroola no rebanho da raça Corriedale conseguiremos ganhos genéticos para a característica de resistência a parasitos gastrointestinais, porém, em contrapartida, uma perda na qualidade da lã.

\section{Productive impact on the inclusion of germplasm Booroola in Corriedale flock}

\section{Abstract}

The purpose of this note is to present some results for the productive impact in the first year of inclusion of germplasm Booroola in a flock of Corriedale. The data were taken from the production of a general flock of Corriedale born in 2013. 25 sheeps were mated with a Booroola Ram (BN) and 50 with two not Booroola Rams (NN). The BN Ram's daughters were more resistant to gastrointestinal parasites. On the other hand, the daughters of NN Ram showed lower values for quality spun and greater comfort factor. With the inclusion of Booroola blood in this flock, genetic gains for resistance to gastrointestinal parasites were obtained.

Keywords: Expected progeny differences. Sheep. Resistance to gastrointestinal parasites.

\section{Referências}

AMARILHO-SILVEIRA, F.; BRONDANI, W. C.; LEMES, J. S. Lã: características e fatores de produção. Archivos de Zootecnia, v. 64, n. R, p. 13-24, 2015a. Disponível em: <http://www.uco.es/ucopress/ az/index.php/az/article/view/502>. Acesso em: 06 jun. 2016.

AMARILHO-SILVEIRA, F.; BRONDANI, W. C.; MOTTA, J. F.; FERREIRA, O. G. L.; LEMES, J. S. Resistência ovina frente a nematoides gastrintestinais. Archivos Zootecnia, v. 64, n. R, p. 1-12, 2015b. Disponível em: <http://www.uco.es/organiza/servicios/publica/az/php/img/web/16_10_40_37_3516_ REVISION_Resistencia_3GUS_FINAL1.pdf>. Acesso em: 06 jun. 2016.

GOLDBERG, V.; CIAPPESONI, G.; BARBIERI, I.; RODRÍGUEZ, A.; MONTOSSI, F. Factores no Genéticos que Afectan la Resistencia a Parásitos Gastrointestinales en Merino en Uruguay. Producción Ovina, Canelones, v. 21, p. 1-11, 2011. Disponível em: <http://www.ainfo.inia.uy/digital/bitstream/ item/3498/1/Produccion-Ovina-2011-v21P2.pdf>. Acesso em: 06 jun. 2016.

INSTITUTO NACIONAL DE INVESTIGACION AGROPECUÁRIA. Evaluaciones genética ovinas. 2011. Disponível em: <http://www.geneticaovina.com.uy/> . Acesso em: 06 jun. 2016.

INTERNATIONAL WOOL TEXTILE ORGANIZATION (IWTO). 2015. Disponível em: <http://www.iwto. org/wool/the-natural-fibre/>. Acesso em: 06 mar. 2016.

NEIMAUR, K.; SIENRA, I.; KREMER, R.; SÁNCHEZ, A. L.; URIOSTE, J. I. Diámetro de la lana y su variabilidad en Corriedale. 1. Asociación fenotípica con características de la lana de medición objetiva. In: V CONGRESO DE LA ASOCIACION URUGUAYA DE PRODUCCION ANIMAL (AUPA), Montevideo 3-4 Diciembre 2014. Disponível em: < http://www.alpa.org.ve/ojs/index.php/ojs_files/article/ viewFile/2518/905>. Acesso em: 06 maio 2016. 
SOUZA, C. J. H.; JAUME, C. M. MORAES, J. C. F. Introdução da mutação Booroola em rebanhos comerciais e avaliação ponderal dos cordeiros (resultados preliminares). In: JORNADAS URUGUAYAS DE BUIATRIA, 34, 2006, Paysandu. Paysandu: Jornadas Uruguayas de Buiatría, v. 34, p. 182-183, 2006.

SOUZA, C. J. H.; MELO, O. E.; MORAES, J. C. F. Genética da prolificidade e seu emprego na produção ovina. Revista Brasileira de Reprodução Animal, n. 6, p. 163-166, 2009. Disponível em: <http:// www.cbra.org.br/pages/publicacoes/rbra/download/p163-166.pdf>. Acesso em: 05 jun. 2016.

\section{Histórico editorial:}

Submetido em: 12/03/2016

Aceito em: 08/06/2016

Como citar:

$\underline{A B N T}$

AMARILHO-SILVEIRA, F. Impacto produtivo na inclusão de germoplasma Booroola em rebanho Corriedale. Revista Agrogeoambiental, Pouso Alegre, v. 9, n. 2, p. 109-115, abr./jun. 2017. Doi: http://dx.doi.org/10.18406/2316-1817v9n22017964

APA

AMARILHO-SILVEIRA, F. (2017). Impacto produtivo na inclusão de germoplasma Booroola em rebanho Corriedale. Revista Agrogeoambiental, Pouso Alegre, 9 (2), 109-115. Doi: http://dx.doi.org/10.18406/2316-1817v9n22017964

$\underline{\text { ISO }}$

AMARILHO-SILVEIRA, F. Impacto produtivo na inclusão de germoplasma Booroola em rebanho Corriedale. Revista Agrogeoambiental, 2017, vol. 9, n. 2, pp. 109-115. Eissn 2316-1817. Doi: http://dx.doi.org/10.18406/2316-1817v9n22017964

\section{VANCOUVER}

Amarilho-Silveira F. Impacto produtivo na inclusão de germoplasma Booroola em rebanho Corriedale. 2017 abr/jun; 9(2): 109-115. Doi: http://dx.doi.org/10.18406/2316-1817v9n22017964 